\title{
TERRITORIALIDADES EN SAN LORENZOY EN BARRANQUERAS EN EL MARCO DE LA HIDROVÍA PARANÁ-PARAGUAY
}

\begin{abstract}
Mariana Schweitzer
Arquitecta (1989), especialista en Planificación Urbana y Regional (1994) y magíster en Planificación Urbana y Regional de la Universidad de Buenos Aires (2001). Miembro de la Carrera del Investigador Científico y Tecnológico del CONICET con sede en el Centro de Investigaciones en Hábitat y Municipios (CIHAM) de la Facultad de Arquitectura, Diseño y Urbanismo de la UBA. En dicha universidad desarrolla actividades docentes como profesora adjunta en la asignatura Planificación Urbana, y es coordinadora académica de la Maestría en Planificación Urbana y Regional. Reviste la Categoría II de la Secretaría de Políticas Universitarias de la Argentina como docente investigadora. Colabora como evaluadora para la Agencia Nacional de Promoción Científica y Tecnológica y para el CONICET, y dirige proyectos de investigación de la Universidad de Buenos Aires y del CONICET. marianaschweitzer@gmail.com.
\end{abstract}

\section{Santiago Petrocelli}

Estudiante avanzado de arquitectura, y desde el año 2013 se desempeña como ayudante docente de la asignatura Planificación Urbana de la Facultad de Arquitectura, Diseño y Urbanismo de la UBA. En octubre del año 2013 obtuvo una beca estímulo UBACyT para desarrollar su trabajo "Capacidad de gestión en municipios en áreas metropolitanas. El caso San Lorenzo" (directora: MARIANA SCHWEITZER). Durante 2012 y 2013 participó como investigador en el proyecto UBACyT "Estrategias, escalas y actores en la producción del territorio. Corredores de transporte: la hidrovía Paraná-Paraguay". En la actualidad se encuentra trabajando para la Dirección de Ordenamiento Territorial del Municipio de Lanús y desarrollando su beca estímulo UBACyT. santiagopetrocelli@gmail.com.

ISNN 1666-6I86. Volumen 17 N. 17 (Noviembre de 20I4) Pp. 005-023 - Recibido: I7-06-I4. Aceptado: 26-09-I4 
1- Se inscribe en el producto del proyecto UBACYT "Estrategias, escalas y actores en la producción del territorio. Corredores de transporte: la Hidrovía Paraná-Paraguay", dirigido por MARIANA SCHWEITZER, que tuvo por objetivo principal analizar la articulación de los proyectos de infraestructura de transporte en los territorios y los efectos resultantes de la inserción de estos en las distintas escalas. Este proyecto devino en dos publicaciones, siendo la final "Estrategias, escalas y actores en la producción del territorio. La Hidrovía Paraná-Paraguay en San Lorenzo y en Barranqueras" la base del presente trabajo.

\section{Resumen}

En el presente trabajo se analiza la emergencia de los proyectos de transporte en la región de la cuenca del Plata, particularmente aquellos vinculados con el Programa Hidrovía Paraná-Paraguay, que dan cuenta de la producción del territorio en distintas escalas. Se observan las formas de territorialización de las grandes inversiones generadas en dos casos locales: San Lorenzo, municipio ubicado en el Gran Rosario (Santa Fe) y receptor de grandes inversiones de empresas transnacionales, y Barranqueras, situado en el Gran Resistencia (Chaco), cuya dinámica económico-productiva es sensiblemente inferior. Se parte de caracterizar el Programa Hidrovía Paraná-Paraguay y los principales proyectos que se vinculan con él, para concluir reflexionando sobre el impacto en territorios, población y actividades, y sobre las tensiones derivadas de un proyecto que fue pensado para atender demandas nacionales y supranacionales sin contemplar las características particulares de los territorios involucrados. ${ }^{1}$

\section{Palabras clave}

Territorio, territorialidades, hidrovía.

\section{TERRITORIAL CHANGES IN SAN LORENZO AND BARRANQUERAS IN THE CONTEXT OF THE PARANÁ-PARAGUAY "HYDROWAY"}

\section{Abstract}

This paper analyzes the emergence of transport projects in the River Plate Basin. In particular those related to the Hidrovía ("Hydroway") Paraná-Paraguay Programme, that reflect the production of territories at different scales. The different spatial impacts of large investments generated in two localized cases are observed: San Lorenzo, a municipality located in the Gran Rosario (Santa Fe) region, site of large investments by transnational corporations, and Barranqueras, located in the Gran Resistencia (Chaco) region, where the economic- productive dynamic is noticeably lower. The paper begins with an explanation of the Hidrovía Paraná-Paraguay Programme, as well as the principal projects linked to it. The conclusions consider the spatial impacts of these projects in terms of population and activities as well as the social and economic tensions derived from them. They were planned to support national and supranational interests but did not contemplate their impacts on the territories involved.

$\underline{\text { Keywords }}$

Territory, territorialities, hidrovía. 


\section{INTRODUCCIÓN}

El concepto de territorialidad, originariamente asociado a los comportamientos animales, es recuperado por la geografía para explicar las lógicas de apropiación del espacio, las relaciones de inclusión y exclusión. ROBERT SACK hace referencia a ciertos patrones espaciales de comportamiento de los actores sociales para controlar áreas y, en ese sentido, define la territorialidad como la "estrategia de un individuo o grupo de afectar, influir o controlar personas, fenómenos y sus relaciones, a través de la delimitación y ejerciendo control sobre un área geográfica", denominada territorio (SACK, 1986: 17).

Siguiendo a SACK, se puede definir el espacio a partir de la acción humana, donde un agente tiene una voluntad de control que se ve asociada con las relaciones de poder inmanentes a cualquier relación social. LoPES DE SOUZA (citado por BENEDETTI, 2011) también vincula al territorio como espacio de disputa, definido y delimitado por y a partir de relaciones de poder, con territorialidades que se constituyen en variadas escalas (temporales y espaciales) y que son producto de conflictivos procesos de apropiación de espacios, del despliegue del accionar de los actores sobre estos. HAESBAERT, asumiendo también una visión totalizadora, sostiene que el territorio es producto de un movimiento combinado de territorialización y desterritorialización del espacio, de relaciones de poder mediadas por el espacio, pero a la vez que poder en sentido simbólico, de apropiación. Y entendiendo ello en múltiples escalas, destaca que hay multiterritorialidades para unos pocos (la elite globalizada), reclusión territorial para otros, y precarización territorial y lucha por el territorio mínimo para muchos (HAESBAERT, 2004). A partir de ello se entiende que en cada sitio, simultáneamente, las personas conviven con diferentes espacialidades, con distintas formas de experimentar o vivir el espacio (Lindon, 2007).

La puesta en servicio de redes de transporte, su distribución, sus características, la concentración y la accesibilidad obedecen a estrategias de ciertos actores al habilitar o viabilizar el usufructo del territorio y de sus recursos, dando respuesta a particulares intereses. Actores diversos, públicos y privados, nacionales y supranacionales, despliegan sus estrategias para apropiarse de espacios y de sus recursos, para producir territorialidades. Ante ello resulta de especial interés, en el presente trabajo, analizar las huellas que proyectos formulados desde ámbitos nacionales y regionales generan en la escena local.

En una primera parte del artículo se contextualiza el Programa para la Hidrovía ParanáParaguay y sus particularidades, para luego identificar los proyectos que para esa área se piensan desde el Estado nacional y desde organismos internacionales. Posteriormente se 
2- Son cinco países: Argentina, Brasil, Paraguay, Uruguay y Bolivia.

3- Dadas las condiciones únicas de los ecosistemas involucrados en la región del pantanal y sus potenciales alteraciones por las obras propuestas, en agosto de 1995 se acordó la supresión del plan de obras para dicho tramo de la hidrovía. (Subsecretaría de Puertos y Vías Navegables, Secretaría de Transporte de la Nación). analizan los procesos de territorialización, en el marco de ese programa, en dos casos de estudio: San Lorenzo en la provincia de Santa Fe y Barranqueras en el Chaco, para luego reflexionar sobre los impactos en esos territorios.

\section{EL PROGRAMA HIDROVÍA PARANÁ-PARAGUAY (PHPP)}

Por sus recursos minerales, el valor de sus bosques y la fertilidad de los suelos, la Cuenca del Plata es la región de Sudamérica con mayor desarrollo productivo y concentración de población. Detenta importantes recursos naturales, y es donde se genera el $70 \%$ del PBI de los países involucrados. ${ }^{2}$ Supera los 100 millones de habitantes, y es salida natural para la producción de extensas regiones del continente.

Si bien en 1969 se empezó a considerar la posibilidad de poner en valor a los ríos de la cuenca para mejorar las condiciones de circulación, fue en 1995 cuando se iniciaron los trabajos en el marco del PHPP. Su objetivo es reducir los costos de transporte por medio de la optimización de la navegación diurna y nocturna durante los 365 días del año y las 24 hs del día, en un tramo de $3442 \mathrm{~km}$, conformado por los ríos Paraguay, Paraná y del Plata, entre Puerto Cáceres (Brasil) y el Puerto Nueva Palmira (Uruguay). Debido a que las márgenes de los ríos y su sedimentación condicionan la navegabilidad, se han realizado trabajos de dragado para posibilitar la circulación de barcos de gran calado en los tramos del sur y de barcazas hacia el norte. Estas obras fueron acompañadas con el desarrollo de un sistema portuario y de transporte terrestre, que permite disponer de accesos competitivos y de una flota adaptada para optimizar la movilización de las producciones regionales hacia los mercados globales.

El Programa de la Hidrovía se inserta en una región de características heterogéneas en aspectos demográficos, sociales, económicos y ambientales. En territorio argentino, ingresa por Formosa, sobre el río Paraguay, y sigue por el Paraná costeando Chaco, Santa Fe, Corrientes, Entre Ríos y Buenos Aires. Su influencia se extiende hacia otras provincias argentinas como Santiago del Estero, Tucumán y Salta, y dentro de la cuenca del Plata, a los estados brasileños de Mato Grosso y Mato Grosso do Sul, a gran parte de Bolivia, casi todo el Paraguay y al litoral oeste del Uruguay. Desde el mismo momento de su formulación, se han generado críticas socio-ambientales que llegaron a producir modificaciones en el proyecto original. ${ }^{3}$

La primera etapa del programa consistió en el dragado del río Paraná desde Punta Indio hasta Puerto General San Martín, a 28 pies, y hacia el puerto de Santa Fe a 25 pies, acom- 
Territorialidades en San Lorenzo y en Barranqueras en el marco de la Hidrovía Paraná-Paraguay

pañado con mejoras en la señalización. Con los trabajos posteriores, el calado hasta Puerto General San Martín alcanzó los 34 pies, y está previsto que llegue a 36 pies en un corto plazo. De esta forma, entre el río de La Plata y Puerto General San Martín pueden circular buques de ultramar y, aguas arriba, barcazas que transportan cargas a granel (cereales, subproductos de cereales, combustibles, aceites y minerales) y contenedores. Entre Puerto General San Martín y Santa Fe se está trabajando en la profundización a 28 pies, y desde Santa Fe al norte el calado actual es de 10 pies, y se discute su aumento a 12 pies (ver mapa N. ${ }^{\circ} 1$ ).

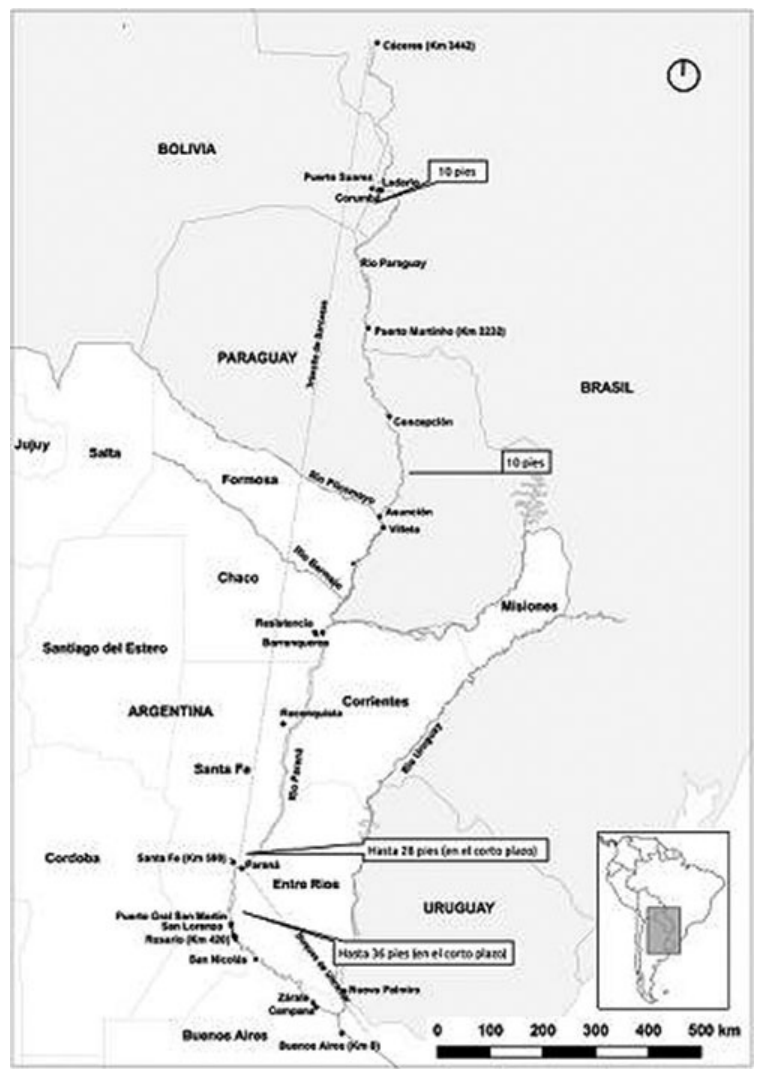

Mapa 1- Hidrovía Paraná-Paraguay Fuente: elaboración propia 
Con el auge de la explotación de la soja desde principios de los años 80 , se estableció una cantidad importante de puertos privados a lo largo de la vía fluvial, que alcanzaron en 2013 un total de 117. Particularmente en el área de Rosafé (Rosario, Santa $\mathrm{Fe}$ ), según los responsables de transporte de la Bolsa de Comercio de Rosario, a lo largo de $67 \mathrm{~km}$ se han localizado 27 terminales, 17 de las cuales están afectadas a productos agrícolas.

\section{LOS PLANES Y LOS PROYECTOS PARA LA REGIÓN DE LA HIDROVÍA PARANÁ-PARAGUAY}

La Iniciativa para la Integración de la Infraestructura Regional Suramericana (IIRSA) es un plan de ordenamiento territorial que incluye proyectos de rutas multimodales, gestado en el año 2000 por organismos multilaterales de crédito y doce países de América del Sur. Busca adaptar los territorios a las exigencias del mercado mundial, y conectar los grandes centros de producción y de consumo con menores tiempos y costos de circulación. Al estar pensada a partir de la demanda, los puertos son piezas clave, ya que funcionan como nodos de articulación y conexión con los mercados globales. La IIRSA contiene obras de transporte, energía y telecomunicaciones distribuidas en ejes denominados "Ejes de Integración y Desarrollo" (EID), uno de los cuales es el Eje de la Hidrovía Paraná-Paraguay.

Por su parte, a nivel nacional, en el año 2004 se comenzó a desarrollar un Plan Estratégico Territorial (PET) en la Subsecretaría de Planificación Territorial de la Inversión Pública. Su intención es lograr un desarrollo más equitativo y equilibrado, y articular la infraestructura con políticas y proyectos vinculados con las dimensiones social, económica y ambiental de cada territorio. Al igual que la IIRSA, el PET propone un conjunto de proyectos de infraestructura de transporte y de energía. Los distintos avances del PET contienen agendas de intervenciones priorizadas desde la escala país, a la vez que iniciativas formuladas como prioridades desde las provincias.

Desde esos planes confluyen proyectos y obras de señalización, iluminación y aumento de calado de la vía fluvial, de mejoras en los puertos, en los ramales de ferroviarios y en rutas que llegan hacia ellos. Se trata de los ferrocarriles Belgrano Cargas, Mesopotámico y Mitre y de las rutas nacionales que conectan los puertos de la hidrovía hacia el oeste y hacia la Mesopotamia y Brasil, siendo las principales las rutas nacionales 81, 89, 16, $33,34,9,12,18$ y 127. 
A nivel provincial, el Chaco ha sumado dentro del PET obras de carácter más local, como nuevos puentes hacia Corrientes y Formosa para el cruce de los ríos y obras de pavimentación en rutas provinciales. En Santa Fe, cuyas rutas están mayormente asfaltadas, los trabajos que se proponen apuntan a mejorar y aumentar las posibilidades de carga a partir de la transformación de las rutas nacionales en autovías y autopistas. En Formosa se incluyen proyectos ferroviarios y viales, y en las provincias de la Mesopotamia se proyectan autovías en las rutas nacionales paralelas a los ríos Paraná y Uruguay (RN 12 y RN 14), puentes binacionales, y particularmente en Misiones y en Entre Ríos, obras en rutas provinciales y en ferrovías para mejorar la conectividad interna.

Algunas de las obras propuestas desde el PET y desde la IIRSA ya fueron concretadas. En ferrocarriles se realizaron trabajos en el Belgrano Cargas para rehabilitar parte de las vías degradadas en los ramales que acceden al puerto de Rosario desde Santiago del Estero, Chaco y Salta, y actualmente se están comenzando nuevas obras en otros quince tramos de ese ferrocarril. En algunas rutas se han realizado algunos trabajos de pavimentación, de transformación en autovías y de mejoras en los accesos a los puertos y en la circunvalación de ciudades.

\section{BARRANQUERAS Y SAN LORENZO. LOS TERRITORIOS LOCALES}

La provincia del Chaco está situada en el nordeste del país. Con poco más de 1 millón de habitantes, tuvo en el último período intercensal (2001-2010) una variación de población menor a la nacional (un crecimiento de $7.2 \%$ ) y una densidad también menor a la media $\left(10,6 \mathrm{hab} / \mathrm{km}^{2}\right)$. Las áreas más densas se ubican sobre el río Paraná y sobre un eje nortesur, que cruza por el centro de la provincia hacia Santa Fe.

Santa Fe está localizada en la región central del país, en una zona agrícola-ganadera por excelencia. Registró cerca de 3,2 millones de habitantes, según datos del Censo Nacional de Población y Vivienda de 2010, y una densidad de población de 24 hab $/ \mathrm{km}^{2}$. También presentó una variación intercensal baja: 6,5\%. Las mayores densidades se registraron en los departamentos sobre el río Paraná.

Los indicadores socioeconómicos del Chaco son de los más desfavorables del país. Fue la provincia que acusó la mayor proporción de población analfabeta, un 5,5\%, mientras que en Santa Fe este valor fue del 1,8\%, habiendo sido la media nacional del 1.9\%. En relación con el hacinamiento, en el Chaco se presentaron valores críticos, con un $38.3 \%$ de su población que vive en hogares de más de dos personas por cuarto, valor que en Santa Fe fue de $24.1 \%$. 
4- En 1918 Atorresagasti, Barges, Piazza y Co., en 1930 un astillero, un aserradero $y$ la empresa de tanino " $Z$ ” (en Puerto Vilelas), Molinos Río de la Plata llegó en 1935 con un establecimiento aceitero, y en 1936 desembarcó La Plomo de la National Lead Company.
En ambas provincias el hacinamiento fue superior a la media nacional del $21.1 \%$. En relación con la pobreza y a la indigencia, el Ministerio de Economía presentó datos para el conjunto de los aglomerados de las provincias, habiendo registrado para Santa $\mathrm{Fe}$ (incluyendo al Gran Santa Fe y al Gran Rosario) un 6.2 \% de su población bajo la línea de pobreza y un $2.4 \%$ en situación de indigencia, mientras que en el Chaco (para el Gran Resistencia) los valores fueron de 14.2 y el $2.3 \%$, respectivamente, muy por encima de la media del país (INDEC, MECON. Fichas provinciales). En el Chaco, las situaciones de mayores carencias se verifican en los departamentos del norte, y en Santa Fe, en los del norte y nordeste.

Muy diferentes resultan los aportes de ambas provincias al PBI nacional. Santa Fe, junto con Córdoba y Buenos Aires, está entre las que más aportan a la economía de Argentina, mientras que el aporte de Chaco es uno de los de menor incidencia. La economía chaqueña está apoyada principalmente en el sector agrícola. Al cultivo tradicional del algodón, a partir de 1979 se le sumaron la soja, el maíz y el girasol. Si bien la actividad algodonera es la más importante, la producción de soja se convirtió, a partir de la campaña 1999/2000, en el principal cultivo en relación con el área sembrada. En paralelo, hubo un aumento en la concentración de la tierra: entre 1988 y 2008 la cantidad de unidades disminuyó en un $18 \%$, y su superficie promedio creció casi en un $50 \%$. Por su parte, Santa Fe tiene una impronta fuerte de su economía primaria, pero también de actividades industriales. La primera está vinculada con el cultivo de soja, fundamentalmente, girasol, maíz y trigo. Según el Censo Nacional Agropecuario de 2002, cerca de la mitad del área implantada era de oleaginosas. El proceso de concentración de la propiedad también se visualiza claramente en Santa Fe: de 300 ha promedio por unidad en 1988, pasó a 451 ha promedio en 2008 , lo que representa un crecimiento del $50 \%$. En cantidad de unidades esto implicó la desaparición de un $28 \%$ de ellas. La provincia es núcleo del procesamiento de oleaginosas, produce leche, maquinarias agrícolas, muebles de madera y automóviles.

En cuanto a las localidades, situada en el departamento de San Fernando, Barranqueras forma parte del Gran Resistencia (ver mapa N. ${ }^{\circ}$ 2). Se asienta sobre un riacho del río Paraná, y a través del puente General Manuel Belgrano se comunica con Corrientes y su capital. Los recursos forestales abundantes, sumados a la facilitación del transporte por vía fluvial, dieron pie a la instalación de los primeros obrajes, y junto a ellos, a fines del siglo XIX, se instaló un aserradero, y en forma posterior lo hicieron las primeras industrias. El puerto fue ampliando sus servicios, y con la llegada del ferrocarril, en las primeras décadas del siglo XX, se instalaron nuevas fábricas asociadas al río ${ }^{4}$, y con ello comenzó la afluencia de población. Su puerto tuvo una intensa actividad, y llegó a ser el tercero en movimiento del país hasta mediados de la década del 70. Debido a la recesión industrial, 
desde los 80 , se formaron en el borde costero "baldíos portuarios" en fábricas, depósitos y puertos desmantelados o subocupados (BENNATO, 2007).

En 2001 Barranqueras contaba con 50.738 habitantes, habiendo crecido respecto del Censo de 1991 en un 19,2 \%. ${ }^{5}$ Se extiende sobre casi cuatro mil hectáreas. Cuenta con doscientas cuadras asfaltadas y una gran cantidad de ripio y de tierra, que dificultan la circulación en días de lluvia. En su ejido se emplazaron conjuntos habitacionales financiados por el Estado, a los que se les adjudica el crecimiento poblacional de los últimos años. Agrupa a dieciocho barrios, muchos de ellos conformados con población migrante de Resistencia y del interior de la provincia, desplazados por el avance de la frontera agraria. La regulación de usos del suelo de la localidad tiene escaso cumplimiento, cuestión que se evidencia en la ocupación de tierras fiscales y privadas en zonas de riesgo hídrico. Respecto de los servicios, la ciudad está mayormente cubierta, a excepción de las cloacas, que solo cubren el $30 \%$ de tejido (correspondiente a los planes de viviendas de los últimos años).

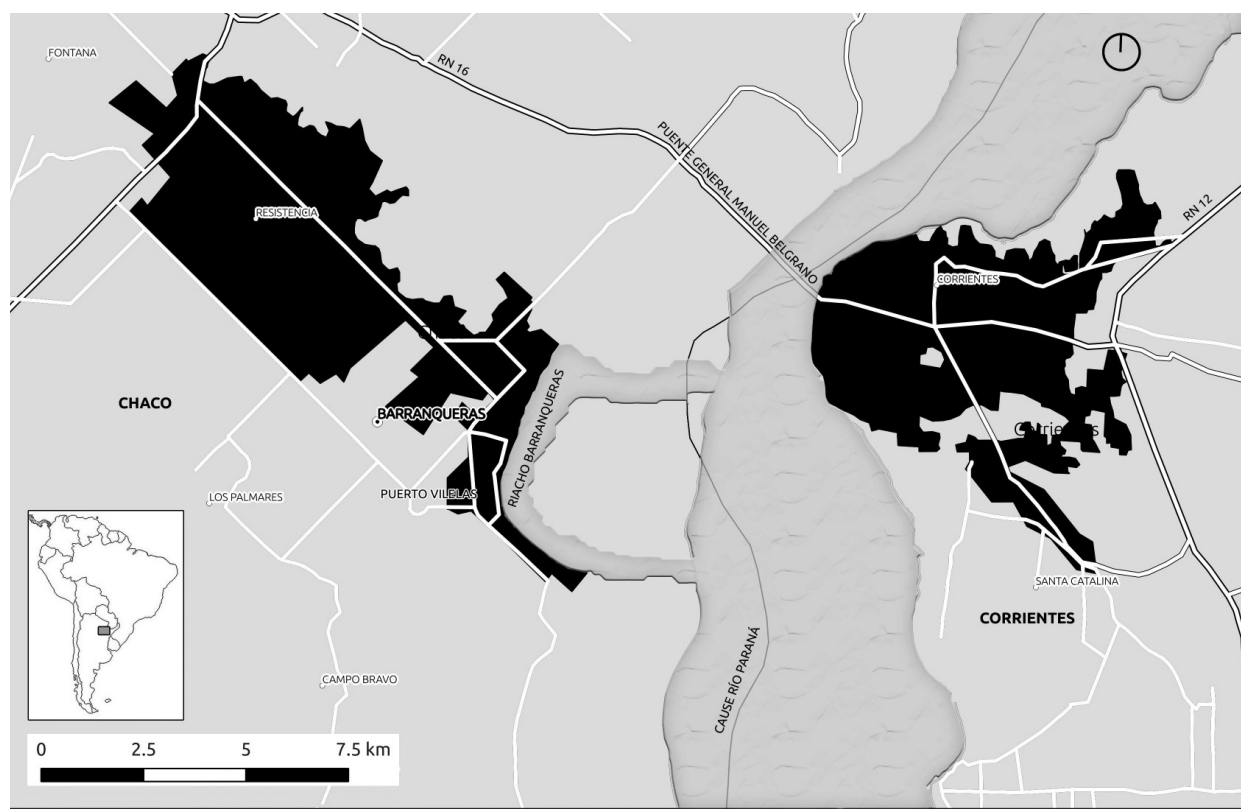

5- Aún no se encuentran disponibles los datos por localidad correspondientes al Censo 2010.

Mapa 2- Barranqueras en su contexto regional Fuente: elaboración propia 
6- Fueron la producción aceitera de la Compañia Sudamericana de Aceites (1884) y la de harina, con la presencia de un molino junto a un embarcadero escocés (1889). En 1900 desembarcó Dreyfus y compró el puerto Granaderos, y en 1904 Drysdale y Rosembaum comenzaron a explotar el primer elevador de granos. A la zona llegaron también establecimientos militares (el Batallón 12 de Infantería, el Arsenal Regional del Litoral y la Fábrica Militar de Munición de Artillería).

7- Según el INDEC, el porcentaje de población que habita en "villas de emergencia" en el departamento de San Lorenzo es del $5,74 \%$ (INDEC-IPEC) (RIGOTTI, 2007).
San Lorenzo está localizada en el norte del aglomerado del Gran Rosario (ver mapa N. ${ }^{\circ} 3$ ). La ocupación del territorio se produjo como producto de la infraestructura vial y ferrovial vinculada con la colonización agrícola, luego de los primeros asentamientos franciscanos. Con la habilitación de los primeros puertos se fueron instalando industrias, aunque se mantuvo un perfil fuertemente apoyado en la agricultura (RigOTTI, 2007). Las actividades manufactureras, ${ }^{6}$ instaladas a partir de la década del 60 , consolidaron un fuerte perfil industrial, y los puertos adquirieron mayor relevancia, constituyéndose la localidad en una gran atractora de población hasta avanzados los años 70 del siglo pasado, cuando desembarcó el modelo neoliberal. Con el desarrollo de la actividad sojera y la exportación de granos y subproductos, se instalaron o ampliaron las plantas de empresas que buscaban una salida fluvial para abaratar sus costos de transporte. En la actualidad, San Lorenzo forma parte del polo exportador más importante del país y del mayor clúster de procesamiento de soja del mundo.

Según el Censo Nacional de 2001, San Lorenzo alcanzó los 43.039 habitantes y, si bien aún no hay datos del Censo de 2010 por localidad, se calcula que viven allí 50.000 personas. Integrado por veintiséis barrios, el crecimiento del tejido residencial se produjo por sumatoria de loteos privados entre los ejes ferroviales, las industrias y los puertos. En cuanto a su infraestructura sanitaria, las cloacas cubren el $70 \%$ de la trama. La falta de cumplimiento de las ordenanzas de usos del suelo se evidencia en problemas ambientales derivados de la convivencia de actividades poco compatibles. Es una ciudad con una importante cantidad de complejos de vivienda de interés social, en tierras distantes del río Paraná, y con asentamientos irregulares en zonas anegables, como en la ribera del arroyo San Lorenzo. ${ }^{7}$ Producto de su conformación, San Lorenzo presenta hoy una significativa fragmentación socio-espacial y una débil calidad urbana.

\section{LA TERRITORIALIZACIÓN DEL PROGRAMA HIDROVÍA EN SAN LORENZO Y BARRANQUERAS}

En ambas localidades, las obras vinculadas con el PHPP han generado transformaciones territoriales, siendo estas más significativas en el caso de San Lorenzo. A su vez, se ha realizado otro tipo de intervenciones de envergadura por fuera del PHPP.

En el año 2009 la Nación y la Provincia de Chaco firmaron un acuerdo con el objetivo de darle mayor operatividad y competitividad al puerto de Barranqueras. La profundidad del riacho era de ocho pies, y hoy se están garantizando diez pies, pudiendo recibir portacontenedores y barcazas. Sin embargo, se señala que los accesos al riacho no están abiertos hacia 
ambos lados, que solo es posible acceder desde la desembocadura hasta YPF, y que al estar la salida obstruida, los buques tienen que hacer maniobras de giro, lo que limita el tamaño de las embarcaciones. ${ }^{8}$ Estas complicaciones, sumadas a conflictos con la gestión del puerto, han derivado en el traslado de algunas empresas hacia la otra orilla del río, a Corrientes, en donde hay mayores facilidades para cargar contenedores. ${ }^{9}$ Para el período 2010-2030, se ha formulado un Plan Maestro del Complejo Portuario de Barranqueras y la zona ribereña de su riacho, financiado por la CAF, que incluye mejoras en accesos, playas de carga y descarga y mejoras en la gestión. ${ }^{10} \mathrm{El}$ puerto y el dragado fueron concesionados por la provincia a fines de 2012 a la empresa COLONO ${ }^{11}$, y el dragado del riacho, con el objetivo de llevarlo a doce pies, fue adjudicado a la empresa COPACRE, una constructora porteña.

Por las vías del Belgrano Cargas circulan escasos trenes que llegan únicamente hasta el puerto y a los silos de la empresa COLONO (Ex Junta Nacional de Granos). Se plantea desde la provincia la construcción de un segundo puente con Corrientes, cuyo proyecto ejecutivo ya tendría financiamiento. ${ }^{12}$ Por su parte, están avanzando obras ferroviarias vinculadas con el corredor Aviá Terai - Barranqueras, que comprenden el cambio de vías en 73 kilómetros. ${ }^{13}$

En el puerto de Barranqueras se realizan actividades de transferencia de cargas, fundamentalmente granos, desde su hinterland hasta San Lorenzo y Rosario, y de contenedores hasta Buenos Aires. Se señala que la mayor actividad se produce en épocas de cosecha, en los meses de mayo y junio, cuando la producción (algodón, soja) llega por camiones al puerto, a través de vías periféricas y sin entorpecer el funcionamiento urbano, a pesar de la

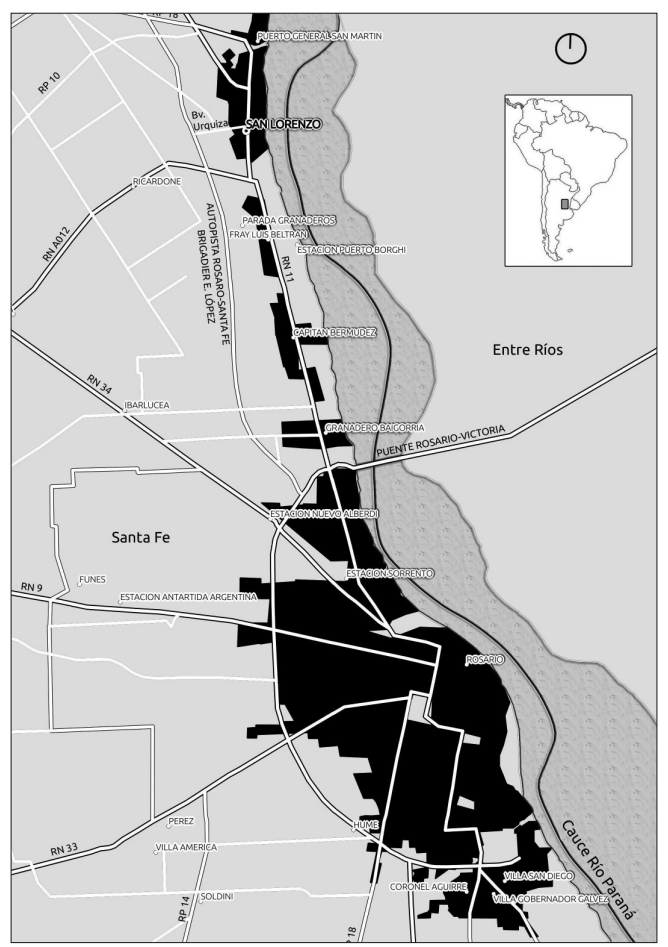

8- Entrevista a JAVIER RUIZ, coordinador de Empleo, Municipalidad de Barranqueras. Se señala también que las dragas no son del puerto, y que las que llegan suelen tener problemas de funcionamiento.

9- El gran movimiento fluvial de los últimos años consiste en la circulación de barcazas de bandera paraguaya por el canal principal, mayormente con producción para ser procesada en los puertos del entorno de Rosario.

10- Fuente: http://www.aic-consultores.com.ar/PMPB/ resumen-cpbv-nota.pdf.

11- Compañía Logística del Norte SA (COLONO) es una sociedad anónima con participación mayoritaria estatal, que está autorizada a contratar en forma directa. Fuente. http://www.prensa.chaco.gov. ar/?pag=noticia \&nid $=29952$ (28/09/2013)

12 Entrevista a HUGO VARELA, ingeniero jefe de Vialidad Provincial.

13- Fuente: http://www.prensa.chaco.gov.ar/?pag=noticia\&nid=26276 (15/02/2013).

Mapa 3- San Lorenzo en su contexto regional

Fuente: elaboración propia 
14- En Cargill se acopia soja que se embarca hacia San Lorenzo y Villa Gobernador Gálvez, donde se procesa o se exporta. Esta planta no opero en 2013 debido a la disminución de la cosecha.

15- En 2012, en Cargill trabajaban diez personas, y en época de cosecha llegaban a un total de veinte. En la terminal de YPF, se emplea en planta permanente a quince personas, $y$ otros treinta como contratados.

16- Fuente: http://www.diarionorte.com/article/94613/ el-ministro-tomada-inaugura-manana-junto-al-gobernador-el-parque-industrialchaco-en-barranqueras (02/09/2013).

17- Fuente: http://industria chaco.gov.ar/pro-industria/ industria-parques-y-zonasindustriales (consulta en octubre de 2014).

18- Fuente: http://www.momarandu.com/amanoticias. php $? a=1 \& b=0 \& c=132513$ (04/09/2013).

19- Para ello han tenido 19- Para ello han tenido
ayuda de Nación y Provincia, que pagan los sueldos durante el periodo de capacitación $y$ entrenamiento y eximen de cargas laborales a las empresas (entrevista a JAVIER RUIZ, coordinador oficina de Empleo). magnitud del fenómeno. En sentido inverso, llega combustible fundamentalmente desde San Lorenzo para su distribución en camiones al NEA y al NOA. Las empresas radicadas en el puerto son YPF, ESSO, Shell; cerealeras, como ACA y Cargill (antes de 2005 Molinos Río de la Plata ${ }^{14}$ ), Abel Bello, AOTSA-Vicentín, la Asociación de Productores Alternativos del Chaco y areneras, como Puerto Antequera, Arenera del Litoral, ALVI o Carlos Piñol. El conjunto de las actividades portuarias no demanda personal en cantidades significativas. ${ }^{15}$

El gobierno provincial puso en marcha en septiembre de $2012^{16}$ el complejo industrial de Barranqueras. Se estima que esta mini-zona industrial, que se localizó estrechamente vinculada con el puerto, generará unos trescientos puestos de trabajo. Se prevé la radicación de inversiones provinciales y extranjeras. Según el gobierno de Chaco, habría once empresas ya establecidas ${ }^{17}$, y se estarían radicando cinco pymes chaqueñas. Por su parte, en septiembre de 2013 se inauguró el primer Parque Industrial Privado de Chaco (Parque Industrial Chaco-PIC) en las instalaciones de la ex Grafa, a metros del puerto. Serían trece las empresas interesadas en el predio industrial. ${ }^{18}$ Entre las empresas radicadas en los parques industriales se encuentran la Procesadora Textil Chaco, una empresa que fabrica bloques para la construcción, otra de cámaras para el servicio de vigilancia, una fábrica de fideos y otra de envasados de agua. ${ }^{19}$

Entre algunas de las obras realizadas en Barranqueras por fuera del PHPP se destaca la construcción en 2004 de un muro de defensa contra las inundaciones ${ }^{20}$, que constituye una importante barrera física que potencia el divorcio de la localidad con el paisaje fluvial.

En San Lorenzo las actividades portuarias están muy presentes, favorecidas con la privatización de los puertos habilitada a partir de 1992. Las terminales fluviales privadas generan un constante movimiento de productos que ingresan en la ciudad, una pequeña parte en trenes $^{21}$, y la gran mayoría en camiones. Los accesos a la localidad se encuentran colapsados, y con ello se identifican dificultades en la movilidad en algunos sectores de la trama urbana, que generan consecuencias sobre el ambiente. ${ }^{22}$ Los usos productivos contaminantes han bloqueado el acceso visual y funcional al río, y los pocos vacíos, como el segmento al norte del arroyo San Lorenzo, comenzaron a ser ocupados por emprendimientos industriales y portuarios, con nulas previsiones infraestructurales. Hacia el sur la faja ribereña ya se encuentra totalmente comprometida con usos industriales y sus futuras extensiones.

El efecto sobre el empleo local, producto de esas actividades, no es muy elevado. Las pymes generan una significativa cantidad de fuentes de trabajo, lo que no ocurre con las grandes industrias, que se están robotizando. ${ }^{23}$ Por otro lado, se observa un importante 
dinamismo en la ciudad, evidenciado en la existencia (en diciembre de 2012) de más de doce edificios en construcción y en el crecimiento de las actividades comerciales.

Partiendo de la base de enfrentarnos a territorios heterogéneos, que fueron configurados respondiendo a distintas lógicas debido a su posición geográfica, las características naturales, las actividades económicas y la acumulación de inversiones en infraestructura, podemos identificar en ambos casos las siguientes problemáticas:

- Conflictos ambientales. Derivados de los cambios en el régimen hidrológico debido a las transformaciones en el uso del suelo, la erosión por la alteración de los patrones de escurrimiento superficial de las aguas, el deterioro en la calidad del recurso y la pérdida de humedales.

- Cambios en la morfología de los territorios. La navegación de los ríos aumentó considerablemente en los últimos años, y las políticas que se impulsan contribuyen a este incremento. Este crecimiento en los flujos tiene su correlato en el retroceso de la barranca del río, que transforma los territorios ribereños y pone en riesgo las edificaciones próximas. ${ }^{24}$

- Conflictos sociales. La expansión sojera y de la frontera agraria, incluso hacia zonas ambientalmente vulnerables, ha generado importantes efectos sociales. Junto al desproporcionado aumento del valor de la tierra, muchos campesinos o miembros de comunidades indígenas con tenencia precaria de la tierra fueron expulsados o presionados por el avance de la soja.

- Permanencia de áreas sin cobertura de servicios. Las inversiones responden a las demandas de las actividades relacionadas con la logística, el comercio y la producción, y no incluyen a las carencias de otros usos. Las obras de infraestructura que se realizan o que se proyectan mayormente apuntan a optimizar la llegada de la producción a los puertos de la hidrovía.

- Poco incremento en el empleo para las poblaciones locales. Las actividades asociadas al PHPP no han aportado a disminuir considerablemente los índices de desempleo.

- Tensiones entre los usos del suelo. A pesar de que la intensidad de usos del suelo es muy diferente en San Lorenzo y Barranqueras, en ambos casos se generan disputas entre las distintas actividades. En San Lorenzo los usos productivos avanzan sobre el tejido residencial, y en Barranqueras, asentamientos precarios se instalan en predios industriales subutilizados.
20- Esto no significa la ausencia de inundaciones, debido a que la ciudad sigue sufriendo esos embates por las lluvias abundantes.

21- Son el Ex Belgrano Cargas (casi sin operación) y el Ex Mitre, que ingresan a los puertos y a las terminales privadas: Terminal 6, $A C A$, Vicentín, La Alumbrera, etc.

\section{2- El subsecretario de Transporte de la Provincia de Santa Fe, en ocasión de la entrevista que se le hizo, comentó que en tiempos de cosecha ingresan 2000 camiones diarios hacia las terminales de Puerto Gene- ral San Martín, 1600 a las de San Lorenzo y otros tantos a las nuevas terminales de Timbúes, que atraviesan el tejido residencial.}

23- El coordinador general de Producción, Desarrollo Local y Turismo de la Municipalidad de San Lorenzo, JULIO CARAMUTO, cita entre ellas a Tubomec, Construmec Tolk, Van Houten, todas pymes locales que crecieron a la sombra de las grandes industrias.

24- Mensualmente son unos cuatrocientos barcos de gran porte los que navegan por el río Paraná frente a Rosario. En su mayoría son buques graneleros o "bulkcarriers", buques tanque, portacontenedores y convoyes de empuje de barcaza (STANCICH, 2007) 


\section{REFLEXIONES FINALES}

El PHPP no es solamente un proyecto de mejora de la navegabilidad, es mucho más que eso. Son nuevos puertos, nuevas actividades, nuevos actores. Es la presencia de todo ello superpuesto sobre una trama urbana, social y económica, sobre actores preexistentes con sus propias territorialidades.

Si bien la superficie de los municipios es similar, la intensidad en los usos del suelo es muy diferente: en San Lorenzo es intensivo por las actividades de las empresas y de sus puertos, mientras que en Barranqueras solo se llevan a cabo actividades de almacenamiento con menos demandas de uso del suelo. Estas diferencias no solo se expresan en las competencias por el suelo urbano, sino también en los distintos requerimientos de accesibilidad, en las actividades complementarias, en la demanda y calificación de la mano de obra y de articulación logística.

El uso intensivo de la costa en San Lorenzo, por la presencia de grandes empresas con sus puertos con múltiples funciones, se traduce en calles con elevado tránsito de transporte pesado que circula entremezclado con otras actividades, y en el olor a azufre y a productos que intervienen en el proceso productivo. Circulan intensamente camiones que atraviesan el tejido y generan problemas edilicios, ruidos molestos y accidentes. La polución sonora y visual, así como el polvillo en el aire y el olor desagradable son señalados por los pobladores junto al reclamo de mejoras en un sistema de salud que no creció a la par de las actividades que allí se desarrollan. Las empresas han avanzado sobre espacios públicos y privados, favorecidas por políticas locales que llegaron a ceder espacios urbanos y a habilitar nuevos usos industriales en zonas residenciales. Se suman también la tensión y el conflicto entre usos residenciales, productivos y recreativos en la costa.

Barranqueras, tercera ciudad del Chaco en cantidad de habitantes, nació y creció gracias a su puerto, el que le dio movimiento comercial, industrial y con ellos trabajo, pero que también la condenó al olvido con su estancamiento y desactivación. La ciudad no ha recobrado el dinamismo y persiste como ciudad dormitorio, olvidando su ribera. Aquí, el proyecto para la hidrovía es más "silencioso", más "sigiloso", aunque con voluntad de cobrar mayor protagonismo con las inversiones previstas por la provincia para lograr una mayor captación de cargas y ampliar el desarrollo de actividades productivas. A pesar de los esfuerzos realizados en la vía fluvial, la ciudad parecería continuar funcionando como patio trasero de la capital del Chaco. 
En ambas localidades, el acceso a la costa del río está mediado por los puertos, habiendo quedado pocos tramos de uso público.

En ninguno de los casos se han identificado grandes migraciones para el desarrollo de actividades, salvo en ocasión de la construcción de las plantas industriales en los puertos de San Lorenzo. Algunos de esos migrantes se establecieron en la localidad, parte de ellos instalados en predios ferroviarios desactivados o en predios no registrados en el catastro municipal. En menor escala sucede en Barranqueras, con población que vive en zonas de vías desactivadas, incluso en áreas portuarias, frente a las empresas. La mayoría son familias que viven de la pesca de subsistencia, que vieron limitada su actividad, y con ello, cualquier tipo de mejora habitacional.

El crecimiento de Barranqueras, en las últimas décadas, fue por la necesidad de viviendas de la ciudad de Resistencia, mientras que en San Lorenzo fue por los usos vinculados con las nuevas actividades y a su rol dentro de la economía global.

En San Lorenzo se han creado fuentes de trabajo asociadas a la Hidrovía, en las plantas y en las actividades portuarias, aunque en volúmenes reducidos debido a la introducción de un elevado desarrollo tecnológico. Se ha mencionado que hay más empleos creados en actividades de apoyo y complementarias, en las pymes de la zona, que en las propias plantas. En Barranqueras, el problema histórico de la falta de trabajo y la dependencia del empleo público, común a todo el NEA, no ha sido revertido por las actividades asociadas al Programa Hidrovía. Debido a que son muy pocos los puestos de trabajo estables en actividades industriales y en las terminales portuarias, una parte considerable de la población de Barranqueras trabaja en Resistencia. Como contrapartida, con la reciente creación del complejo industrial, estrechamente vinculado con el puerto, se estima dar una respuesta parcial a esta demanda.

En relación con los actores en el territorio, si bien en ambos municipios se radicaron empresas multinacionales, en el caso del complejo portuario de San Lorenzo su presencia es más evidente. Así como la presencia de las empresas en la costa es más intensa, el actor privado es el factor dinamizador de la economía (y la principal fuente de conflictos con los vecinos, producto del avance sobre los barrios). En Barranqueras, por el contrario, el gobierno provincial es el que busca estimular el desarrollo de un puerto cuyo movimiento es sensiblemente menor.

Dentro de la hidrovía se han construido territorialidades diversas. Los actores con sus acciones territorializan, construyen territorialidades particulares, superpuestas y en diferentes 
escalas, con mayores o menores aspiraciones de dominación o transformación de territorios, de controlar personas o recursos para obtener ganancias o para mejorar las condiciones de competencia. El Estado en sus distintos niveles, mediante la puesta en marcha del PHPP o por medio de planes y proyectos o normativas de ordenamiento territorial (inclusive con la falta de control), las grandes empresas (la elite globalizada) que diseña sus espacios de extracción de recursos, de procesamiento y de exportación, y las poblaciones locales o los grupos sociales mediante sus resistencias u ocupación de territorios mínimos construyen sus particulares territorialidades. La hidrovía se planteó mejorar la navegabilidad y reducir los costos de transporte para la producción, fundamentalmente sojera, hacia mercados externos, y a estos objetivos parece estar dando respuestas. Los objetivos vinculados con el desarrollo de las regiones y de las poblaciones, incluidos en la formulación del proyecto, parecen haberse quedado solamente como enunciados.

\section{BIBLIOGRAFÍA}

BENEDETTI, Alejandro (2011). "Territorio: concepto integrador de la geografía contemporánea”. En: Territorio, lugar, paisaje. Prácticas y conceptos básicos en geografía. Patricia Souto (coordinadora). Editorial de la Facultad de Filosofía y letras, UBA, Buenos Aires.

BENNATO, Aníbal (2007). “Los espacios públicos y el frente fluvial del Paraná en Área Metropolitana del Gran Resistencia. El caso de la ciudad de Barranqueras". En: IPURBAT, Facultad de Arquitectura y Urbanismo, Universidad Nacional del Nordeste, Salta. BORGES, Julio César (2007). "El papel de infraestructura vial en la expansión urbana. El caso de la Ciudad de Barranqueras". En: Seminario sobre Políticas Urbanas, Gestión Territorial y Ambiental para el Desarrollo Local. IPUR FAU UNNE, Chaco.

GODOY, Susana; SCORNIK, Marina y TRABALÓN, José (2004). "Marco normativo del uso y ocupación del suelo en las localidades de Barranqueras y Fontana". Ponencia presentada en III Jornadas de Investigación, Docencia, Extensión y Gestión. UNNE, Chaco.

HAESBAERT, Rogerio (2004) O mito da desterritorializaçao: do "fim dos territórios" a "multiterritorialidade". 3. ${ }^{\text {a }}$ ed. Rio de Janeiro: Bertrand Brasil. Brasil.

INICIATIVA PARA LA INTEGRACIÓN DE LA INFRAESTRUCTURA REGIONAL SURAMERICANA, IIRSA, Base de datos de proyectos. En: www.iirsa.org (consultado en agosto de 2013).

INSTITUTO NACIONAL DE ESTADÍSTICA Y CENSOS (INDEC) Censo Nacional de Población, Hogares y Viviendas 2001 (consultado en noviembre de 2012). 
INSTITUTO NACIONAL DE ESTADÍSTICA Y CENSOS (INDEC) Censo Nacional Agropecuario 2002. En: http://www.indec.gov.ar/agropecuario/cna_defini.asp (consultado en marzo de 2013).

INSTITUTO NACIONAL DE ESTADÍSTICA Y CENSOS (INDEC) Censo Nacional Agropecuario 2008 Resultados provisorios. En: http://www.indec.gov.ar/default_cna.htm (consultado en marzo de 2013).

INSTITUTO NACIONAL DE ESTADÍSTICA Y CENSOS (INDEC) Serie Encuesta Nacional Agropecuaria 1993-2005. En: http://www.indec.gov.ar/principal.asp?id_te$\mathrm{ma}=10311$ (consultado en marzo de 2013).

LINDON, Alicia (2007). "Espacialidades, desplazamientos y trasnacionalismo". En: Papeles de población N. ${ }^{\circ}$ 53. Julio-septiembre. Toluca, Universidad Autónoma del Estado de México, México.

MAEDER, Ernesto; GUTIÉRREZ Ramón (1995) Atlas Histórico del Nordeste Argentino. Instituto de Investigaciones Geohistóricas, CONICET, UNNE, Chaco.

MINISTERIO DE INDUSTRIA, EMPLEO Y TRABAJO DE LA PROVINCIA DEL CHACO. http://economia.chaco.gov.ar/ (consultado en julio de 2013).

MINISTERIO DE INTERIOR Y TRANSPORTE, SECRETARÍA DE TRANSPOR-

TE. Dragado del riacho barranqueras. En: http://www.transporte.gov.ar/content/acciones_dragadodelriachob_1320696808/(consultado en julio de 2013).

MINISTERIO DE PLANIFICACIÓN FEDERAL INVERSIÓN PÚBLICA Y SERVICIOS, MINISTERIO DE TRANSPORTE, SECRETARÍA DE PUERTOS Y VÍAS NAVEGABLES (2008) Plan Maestro y Director del Sistema de Navegación troncal. Visión Estratégica y Bases para su Formulación en el Río Paraná.

MINISTERIO DE PLANIFICACIÓN FEDERAL INVERSIÓN PÚBLICA Y SERVICIOS, MINISTERIO DE TRANSPORTE, SECRETARÍA DE PUERTOS Y VÍAS NAVEGABLES. Hidrovía Paraná Paraguay. En: http://www.sspyvn.gov.ar/hvia_info. html\#flujos (consultado en noviembre de 2012).

MUNICIPALIDAD SAN LORENZO. http://www.sanlorenzo.gov.ar/ (consultado en agosto de 2013).

OPERADORA FERROVIARIA SOCIEDAD DEL ESTADO. http://www.sofse.gov. ar/ (consultado en julio de 2013).

RIGOTTI, Ana María (2007). "Plan de ordenamiento territorial de la costa del área metropolitana del Gran Rosario - Cordón Norte". Presentado ante el Consejo Federal de Inversiones, Santa Fe.

SACK, Robert (1986) Humena Terrytoriality. Its Theory and History. Editorial Cambridge University Press, Estados Unidos. 
SCHWEITZER, Mariana; LARRAIN, Cecilia (2012) Transporte y Territorio. Planes y proyectos para Argentina. Editorial Cuentahílos, Buenos Aires.

SCHWEITZER, Mariana (2013). "Grandes inversiones y conflictos socio-territoriales. Efectos de la localización de terminales portuarias en dos localidades de la Hidrovía Paraná Paraguay”. En: Acta Cientifica del XXIX Congreso de la Asociación Latinoamericana de Sociología, Santiago de Chile.

SCHWEITZER, Mariana; FRASCHERI Federico; PETROCELLI, Santiago (2013). "Los actores en la producción del territorio. El caso de San Lorenzo, Santa Fe". Ponencia presentada en IV Jornadas de Historia de la Industria y los Servicios, Mesa Políticas públicas y de promoción. Facultad de Ciencias Económicas, Universidad de Buenos Aires, Buenos Aires.

SCHWEITZER, Mariana; CARENA, María; FRASCHERI, Federico; LARRAIN Cecilia; PETROCELLI, Santiago (2013) Estrategias, Escalas y Actores en la Producción del Territorio. Corredores de transporte: La Hidrovía Paraná-Paraguay. Editorial Cuentahílos, Buenos Aires.

SCORNIK, Carlos (1998). "Diagnóstico expeditivo del área metropolitana del Gran Resistencia, Informe General". Ministerio del Interior. Resistencia, Chaco.

SECRETARÍA DE POLÍTICA ECONÓMICA Y PLANIFICACIÓN DEL DESARROLLO, Ministerio de Economía y Finanzas Públicas. Fichas provinciales en: http:// www.mecon.gov.ar/peconomica/basehome/fichas_provinciales.htm (consultado en septiembre de 2013).

STANCICH, Elba (2007). “Erosión de islas y barrancas del río Paraná. ¿Solo es la naturaleza? Ríos para la vida". En: http://tallerecologista.org.ar/menu/archivos/ErosionIslas2007. pdf, documentos e informes de Taller Ecologista, Rosario, Santa Fe.

SUBSECRETARÍA DE PLANIFICACIÓN TERRITORIAL DE LA INVERSIÓN PÚBLICA, Ministerio de Planificación Federal, Inversión Pública y Servicios (2008) Plan Estratégico Territorial, Avance 2008.

SUBSECRETARÍA DE PLANIFICACIÓN TERRITORIAL DE LA INVERSIÓN PÚBLICA, Ministerio de Planificación Federal, Inversión Pública y Servicios (2011) Plan Estratégico Territorial Avance II: Territorio e Infraestructura, 2011.

SUBSECRETARÍA DE PUERTOS Y VÍAS NAVEGABLES, SECRETARÍA DE TRANSPORTE DE LA NACIÓN. http://www.sspyvn.gov.ar/hvia_moduloB1.html (consultado en octubre de 2013)

Material periodístico

http://eldiariodelaregion.net/web/el-casco-historico-de-barranqueras-expuso-sobre-salvataje-patrimonial/\#sthash.METVaXr7.dpuf. (19-09-2012). 
http://www.diarionorte.com/article/94613/el-ministro-tomada-inaugura-manana-junto-algobernador-el-parque-industrial-chaco-en-barranqueras (02-09-2013).

http://www.momarandu.com/amanoticias.php? $\mathrm{a}=1 \& \mathrm{~b}=0 \& \mathrm{c}=132513$ (04-09-2013).

http://www.prensa.chaco.gov.ar/?pag=noticia\&nid=25352 (06-02-2012).

http://www.prensa.chaco.gov.ar/?pag=noticia\&nid=26276 (15-02-2013).

http://www.prensa.chaco.gov.ar/?pag=noticia\&nid=26394 (22-02-2013).

http://www.prensa.chaco.gov.ar/?pag=noticia\&nid=29881 (25-09-2013).

http://www.prensa.chaco.gov.ar/?pag=noticia\&nid=29952 (28-09-2013).

\section{Entrevistas citadas}

Gerardo Luna, Terminal Vicentín, San Lorenzo.

Gustavo Peirano, subsecretario de Transporte de la Provincia de Santa Fe.

Hugo Varela, ingeniero jefe de Vialidad Provincial.

JAVIER RUIZ, coordinador de Empleo, Barranqueras.

Julio Caramuto, coordinador general de Producción, Desarrollo Local y Turismo, San Lorenzo.

LuIS FinOLI, subsecretario de empleo, San Lorenzo.

Luis Palermo y Alfredo Sese, Comisión de Transporte de la Bolsa de Comercio de Rosario.

Oscar Bonfanti, subsecretario de Obras y Servicios Públicos, Municipalidad de Resistencia.

Raúl Guex, gerente del Puerto de Barranqueras.

Roberto Benítez, interventor del Puerto de Barranqueras. 